\title{
MTHFR A1298C Homozigot Gen Polimorfizmi Olan Süt Çocuğunda Akut İskemik İnme: Olgu Sunumu
}

\section{Acute Ischemic Stroke in an Infant with MTHFR A1298C Homozygous Mutation: A Case Report}

\author{
Burçin Nazlı Karacabey ${ }^{1}$ (D) Nur Aydınlı ${ }^{1}$ (D) Mine Çalışkan ${ }^{1,2}$ (i)
}

${ }_{1}^{1}$ Istanbul Üniversitesi, İstanbul Tıp Fakültesi, Çocuk Sağı̆ğı ve Hastalıkları Anabilim Dalı, Çocuk Nörolojisi Bilim Dalı, İstanbul, Türkiye

${ }^{2}$ İstanbul Üniversitesi, Çocuk Sağlığı Enstitüsü, Pediatrik Temel Bilimler Anabilim Dalı, İstanbul, Türkiye

ORCID ID: B.N.K. 0000-0001-8857-4356; N.A. 0000-0003-0492-3411; M.C.. 0000-0002-6869-3937

Atıf/Citation: Karacabey BN, Aydinli N, Caliskan M. MTHFR A1298C homozigot gen polimorfizmi olan süt çocuğunda akut iskemik inme: Olgu sunumu. Çocuk Dergisi - Journal of Child 2020;20(1):36-39. https://doi.org/10.26650/jchild.2020.1.0007

Öz

Akut iskemik inme (acute ischemic stroke-AIS) çocuklarda nadir görülmekle beraber nörolojik morbiditenin önemli nedenlerinden biridir. Çocukluk çağında AIS etyolojisinde kardiyak patolojiler, serebral arteriopatiler, hiperkoagülasyon, enfeksiyonlar, ilaçlar, inflamatuar ve otoimmün nedenler yer almaktadır. Bu makalede hiperkoagülasyona genetik yatkınlığı olan, multifaktöriyel risk faktörleri eklenince AIS kliniği ile gelen bir süt çocuğu sunulmakta olup; AIS olgularında tanı aşaması, altta yatan etyoloji, süreci etkileyen risk faktörleri, akut dönem tedavi, ikincil basamak tedavi ve beraberinde koruyucu yaklaşımın prognoz üzerindeki etkisi tartışılmıştır.

Anahtar Kelimeler: Akut iskemik inme, MTHFR A1298C, homosisteinemi, süt çocuğu
ABSTRACT

Acute ischemic stroke is rare in children, but it is one of the important causes of neurological morbidity. The etiology of AIS in childhood includes cardiac pathologies, cerebral arteriopathies, hypercoagulation, chemicals, drugs, inflammatory and autoimmune causes. In this article, we present an infant who has a genetic predisposition to hypercoagulation and comes with AIS clinic when multifactorial risk factors are added. The diagnosis, the underlying etiology, the risk factors affecting the process, the treatment of acute phase, the secondary treatment and the associated preventive approach on prognosis were discussed.

Keywords: Acute ischemic stroke, MTHFR A1298C, homocysteinemia, infant

\section{GiRiş}

Çocukluk çağında AIS insidansı yılda 100 000'de 1,3 ile 13 arasında değişmekte olup nörolojik morbiditenin önemli nedenlerinden biridir. Çocukluk çağında AIS etyolojisinde kardiak patolojiler, serebral arteriopatiler, hiperkoagülasyon, enfeksiyonlar, ilaçlar, inflamatuar ve otoimmün nedenler yer almaktadır. Hiperkoagülasyona yatkınlık oluşturan genetik nedenlerden biri MTHFR genindeki değişimlerdir. MTHFR gen polimorfizmleri homosistein düzeylerini yükseltmekte ve vasküler hastalıklar için risk oluşturmaktadır. MTHFR C677T gen polimorfizmi arteriyel iskemik inmede risk faktörü iken; MTHFR A1298C gen polimorfizminin arteriyel inme üzerindeki rolü tartş̧malıdır. Bu makalede AIS nedeni ile başvuran etyolojide MTHFR A1298C homozigot gen polimorfizmi ve hiperhomosisteinemi saptadığımız süt çocuğuna yaklaşım sunulmaktadır.

\section{VAKA}

Öncesinde sağlıklı 7 aylık erkek hasta, iki gün önce başlayan sol kol ve bacakta güçsüzlük, gülerken ağız kenarında sağa kayma şikayeti ile başvurdu. Özgeçmişinde intrauterin dönemde saptanan musküler tip küçük ventriküler septal defekt hariç özellik yoktu. Soygeçmişinde anne-baba birinci derece akraba idi. Hastanın yapılan başvuru muayenesinde üst solunum yolu enfeksiyonu bulguları mevcuttu. Nörolojik muayenesinde sol elini, kolunu ve bacağını az kullandığı, sol üst-alt ekstremitede kas gücünün $3 / 5$ olduğu, aynı taraf derin tendon reflekslerinde artış olduğu saptandı. Hasta sol hemiparezi nedeni ile yatırıldı. Hafif dehidratasyonu olan hastaya intravenöz sıvı başlandı. Ekokardiyografisi ve tansiyonu normal olan hastada kardiyak kaynaklı patoloji düşünülmedi. Geliş trombositleri $940 \times 10^{3} /$ uL olan hastada hidrasyon sonrası trombosit değerleri

Sorumlu Yazar/Corresponding Author: Burçin Nazlı Karacabey E-mail: bnazlikaracabey@hotmail.com

Başvuru/Submitted: 20.06.2019 • Revizyon Talebi/Revision Requested: 01.10.2019 • Son Revizyon/Last Revision Received: 01.10.2019 • Kabul/Accepted: 02.10.2019 

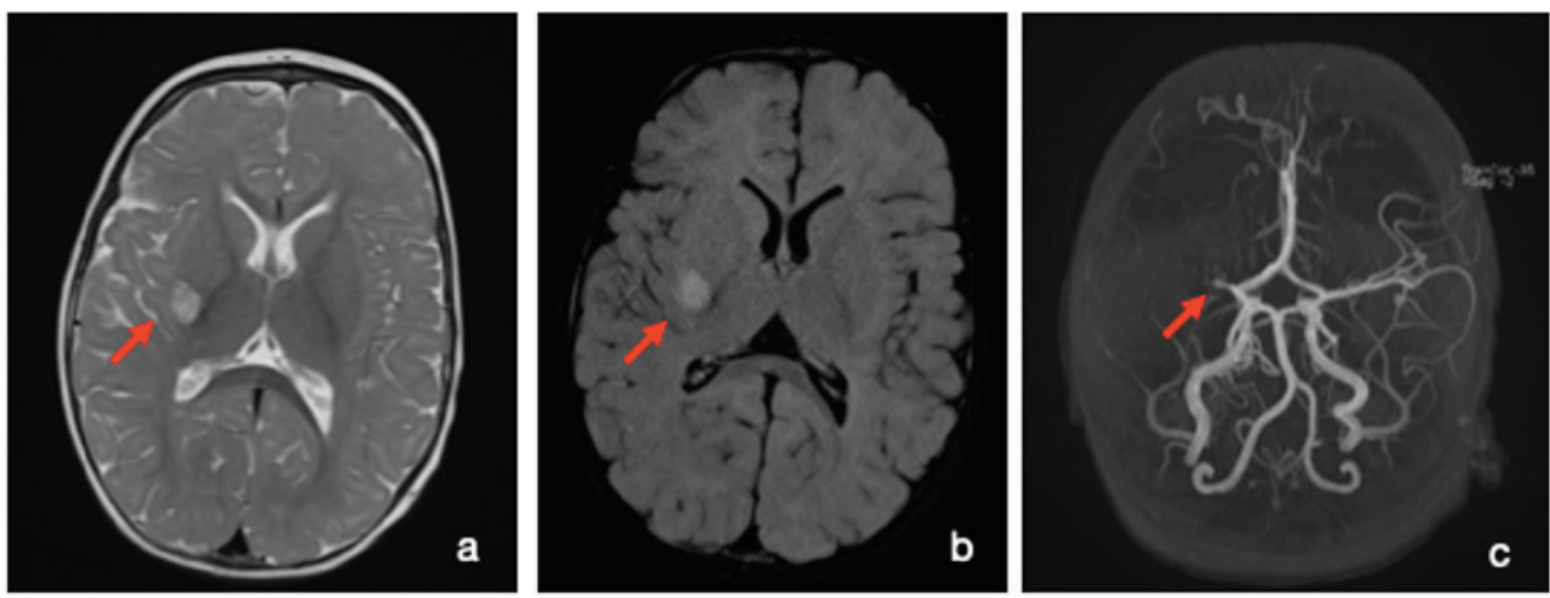

Resim 1 a ve b: Kranial MRG, sırasıyla T2 ve T2 FLAIR sekanslarda sağda lentiform nükleus posterior kesminde, internal kapsül posterior bacağında, temporal, kısmen parietal akut-subakut iskemik lezyonlar. c: MR anjiografi, sağ MCA trunkus düzeyinde, proksimal 1. cm'de oklüzyon, lateral lentikülositriat arterler kısmen seçilebilmekte.

normale döndü. Hastanın yapılan kranial manyetik rezonans görüntülemesinde (MRG), akut ve subakut iskemik lezyonlar olduğu; kranial manyetik rezonans anjiografisinde (MRA), sağ orta serebral arter (middle cerebral artery, MCA) trunkus düzeyinde tam tıkanık olduğu saptandı (Resim 1). AIS nedeni ile $1 U / k g$ düşük molekül ağırlıklı heparin başlandı ve anti faktör $X a$ ile takibi yapıldı. AIS etyolojisi açısından yapılan tromboz panelinde; Faktör V Leiden ve Protrombin G20210A mutasyonu, antifosfolipid antikorları, protein $\mathrm{C}$, protein $\mathrm{S}$, antitrombin eksikliği saptanmazken, homosistein düzeyi hafif yüksek 20 umol/L (n:3,3-8,3 umol/L), MTHFRA1298C homozigot gen polimorfizmi saptandı. Folik asit, B6 ve B12 vitamini başlandı. Yatışının 9. gününde sol üst-alt ekstremitede kas gücü $4 / 5$ olan hasta kısmi iyileşme ile taburcu edildi. Fizik tedavi başlandı. Düşük

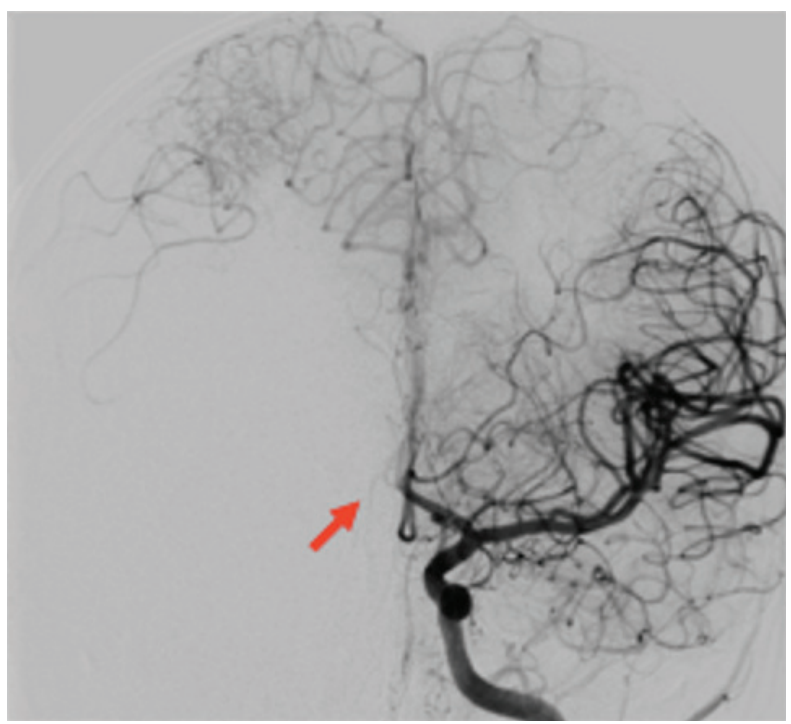

Resim 2 DSA: Sağ MCA anterior temporal trunkusu verdikten sonra total olarak tıkanmakta. Sağ MCA süperior ve inferior trunkus geriye doğru anterior serebral arter ve orta serebral arter leptomeningeal kolletarallerinden yavaş olarak dolmakta. molekül ağırılıklı heparin 14 güne tamamlanıp 5 mg/kg/gün aspirin başlandı. Hastanın 9 ay sonra yapılan girişimsel serebral anjiografisinde (Dijital substraksiyon anjiyografi- DSA) MCA'nın, anterior temporal trunkusu verdikten sonra tam tikanık olduğu ve geriye doğru kolletarallerden dolduğu gösterildi (Resim 2). Beyin cerrahisi endovasküler cerrahiye gerek olmadığını, mevcut antiagregan tedavinin devam etmesini önerdi. Hastanın 1,5 yıl sonra kısa süreli sağ kolda tireme, dalma şeklinde nöbeti oldu. Elektroensefalografisinde (EEG) sağ sentro-fronto-temporo-parietal bölgelerde keskin dalga aktivitesi görüldü. Hastaya oskarbamazepin başlandı. Tekrarlayan nöbeti olması üzerine topiramat eklendi ve nöbetleri kontrol altına alındı. Hastanın 4 yıllık takibinde aspirin, folik asit, B6 ve B12 vitamini tedavisine devam edildi. Sıkı nöbet ve enfeksiyon kontrolü yapıldı ve dehidratasyondan kaçınıldı. Bu süre içerisinde AIS tekrarı olmadı. Hastanın son muayenesinde kas gücü sol üst-alt ekstremitede normalden ayrımı güç olacak şekilde 4/5-5/5 şeklinde ölçüldü. Hastanın çok hafif kognitif etkilenmesi mevcut olup normal günlük aktivitelerine devam etmekte, gözetmen kontrolünde yüzmekte ve ata binebilmektedir.

\section{TARTIŞMA}

AIS çocuklarda nörolojik morbiditenin önemli nedenlerinden biridir. Yapılan çalışmalarda çocukluk çağı AIS insidansı yılda 100 000'de 1,3 ile 13 arasında değişmektedir (1). Etyolojide birçok neden var olup MTHFR gen polimorfizmi bunlardan biridir. MTHFR gen polimorfizmi MTHFR enzim aktivitesini azaltmakta ve homosistein düzeylerini yükseltmektedir. Homosistein düzeyi endotelyal hücrelerin fonksiyonlarında önemli bir role sahip olup yüksek düzeylerde vasküler hastalıklar için bir risk faktörüdür (2). MTHFR C677T polimorfizmi arteriyel iskemik inmede risk faktörü iken; MTHFR A1298C polimorfizminin arteriyel inme üzerindeki rolü tartş̧malıdır ve bu konu ile ilgili çelişkili yayınlar mevcuttur (3). Bizim vakamızda etyolojide MTHFR geninde homozigot $A 1298 C$ polimorfizmi saptanmışt ve buna bağlı homosistein düzeyi hafifçe yükselmiştir. Ayrıca başvuru anındaki risk faktörleri; enfeksiyon, dehidratasyon ve 
hemokonsantrasyona bağlı trombositozunun olması tromboz etyolojisini açılamakta olup çocukluk çağında AIS'in multifaktöriyel geliştiğinin göstergesidir.

AIS çocukluk çağında göreceli nadir görülmesi tanıyı geciktirmektedir. Mallick AA ve arkadaşlarının yaptığı bir çalışmada başlangıç semptomu ile tanı arasında ortalama 24 saatlik gecikme olduğu gösterilmiştir (4). Tanıdaki bu gecikme akut dönem tedavileri arasında olan intavasküler tromboliz veya endovasküler trombektomi için terapötik pencere zamanını aşmaktadır. Ayrıca bu tedavilerin çocuk yaş grubunda uygulanması tartışmalı olup yeterli sayıda çalışma yoktur (5). Bu yüzden akut dönem tedavide; yeterli oksijenasyonun ve hidrasyonun sağlanması, yeterli serebral perfüzyon için hipotansiyondan kaçınılması, nöbetlerin kontrol altına alınması, ateş ve enfeksiyonun kontrol altına alınması esastır. İkincil korumada ise tedavinin temelini heparin, warfarin, aspirin gibi antitrombotik tedaviler oluşturmaktadır (6). Düşük molekül ağırlıklı heparinin ve aspirinin non-randomize prospektif bir çalışmada AIS tekrarında birbirine üstünlüğü olmadığı gösterilmiştir (7). Hiperhomosisteinemisi olan olgularda ek olarak folik asit, B6 ve B12 vitamini takviyesi ile homosistein düzeyleri düşmektedir (8). Bahsi geçen vakamızda geriye dönük aile bireyleri tarandığında; annede MTHFR homozigot C1298C gen polimorfizmi, babada MTHFR heterozigot $\mathrm{A} 1298 \mathrm{C}$ gen polimorfizmi, kız kardeşte MTHFR homozigot $A 1298 C$ gen polimorfizmi saptanmıştir. Aile bireylerine profilaktik folik asit, B6 ve B12 vitamini başlanmıştır. Bu şekilde aile bireylerine tanı koyduğumuz iki vakamız daha mevcuttur. Bunlardan ilki 6 aylıkken sağ hemiparezi ile başvuran bir erkek hastadır. Tetkiklerinde perinatal döneme ait sağ MCA'da tıkanıklık ve MTHFR homozigot $A 1298 C$ gen polimorfizmi saptandı ve tedavi başlandı. Aile taraması sonucu, anne ve babada hem MTHFR homozigot A1298C gen polimorfizmi hem FXIII mutasyonu, babada ayrıca hipertrigliseridemi saptandı ve profilaktik tedavi başlandı. Bir diğeri ise perinatal inme nedeni ile tetkik edilen bir kız hasta idi. Hiperhomosisteinemi, hipertrigliseridemi, MTHFR heterozigot A1298C gen polimorfizmi ve MTHFR heterezigot C677T gen polimorfizmi saptandı. Erkek kardeşinde de hiperhomosisteinemi hipertrigliseridemi MTHFR heterezigot A1298C gen polimorfizmi ve MTHFR heterezigot C677T gen polimorfizmi saptandı. Anne ve babasıda benzer tanı alan olgunun ailesine profilaktik tedavi başlandı.

Prospektif kohort bir çalışmada, AIS geçiren 95 çocuğun 7 yıllık takibinde mortalite $\% 14$, tekrarlama riski $\% 6$ ve $\% 55^{\prime}$ inde hemiparezi, \%21'inde konuşma bozukluğu \%15'inde ise ebeveynlerinin psikolojik veya psikiyatrik bozukluk bildirilmiştir (9). Bizim vakamızda DSA'da beynin sağ yarımında dolaşımın büyük ölçüde etkilendiği görülmektedir. Buna rağmen hastanın motor ve bilişsel fonksiyonları beklenenden iyidir. Bunun öncelikli sebeplerinden biri sağ serebral arterin arka sistem kollateralinden besleniyor olmasıdır. Bir diğer önemli nedeni ise iyi hasta yönetimi, takibi ve aile eğitimidir. Akut dönemde enfeksiyon kontrolü ve hidrasyonun sağlanması, antitrombotik tedavinin başlanması ve devamı, uzun vadede fizik tedavi, enfeksiyondan ve dehidratasyondan kaçınma ve nöbet kontrolü ile koruyucu yaklaşım yapılması, hastanın motor ve bilişsel fonksiyonları normale yakın seyretmesini sağlamıştır.

\section{SONUÇ}

Sonuç olarak MTHFR A1298C gen polimorfizmin AIS ile ilşikisi tam net olmamakla birlikte, başka bir etyolojiyle açıklanamayan AIS'li hastalarda hafif yüksek homosistein düzeyleri ile birlikte MTHFR A1298C gen polimorfizmi görülebilmektedir. Bu hastalarda antitrombotik tedaviler kadar koruyucu hekimliğin, iyi hasta takibinin ve aile eğitiminin prognoz üzerinde önemli etkileri vardır. Bu hastalarda ayrıca ebeveyn ve kardeşler taranarak tanı konabileceği ve profilaktik tedavi başlanarak olası AIS vakalarının önüne geçilebileceği unutulmamalıdır.

Bilgilendirilmiş Onam: Katılımcılardan bilgilendirilmiş onam alınmıştır.

Hakem Değerlendirmesi: Dış bağımsız.

Yazar Katkıları: Çalışma Konsepti/Tasarım- B.N.K., N.A., M.Ç.; Veri Toplama- B.N.K., N.A., M.Ç.; Veri Analizi/Yorumlama- B.N.K., N.A., M.C.; Yazı Taslağı- B.N.K., N.A., M.Ç.; İçeriğin Eleştirel İncelemesi- B.N.K., N.A., M.Ç.; Son Onay ve Sorumluluk- B.N.K., N.A., M.Ç.

Çıkar Çatışması: Yazarlar çıkar çatışması beyan etmemişlerdir.

Finansal Destek: Yazarlar finansal destek beyan etmemişlerdir.

Informed Consent: Written consent was obtained from the participants.

Peer Review: Externally peer-reviewed.

Author Contributions: Conception/Design of Study- B.N.K., N.A., M.Ç.; Data Acquisition- B.N.K., N.A., M.Ç.; Data Analysis/InterpretationB.N.K., N.A., M.Ç.; Drafting Manuscript- B.N.K., N.A., M.Ç.; Critical Revision of Manuscript- B.N.K., N.A., M.Ç.; Final Approval and Accountability- B.N.K., N.A., M.Ç.

Conflict of Interest: Authors declared no conflict of interest.

Financial Disclosure: Authors declared no financial support.

\section{KAYNAKLAR/REFERENCES}

1. Mallick AA, Ganesan V, O'Callaghan FJ. Mortality from childhood stroke in England and Wales, 1921-2000. Arch Dis Child 2010;95:12-9.

2. Homocysteine Studies Collaboration. Homocysteine and risk of ischemic heart disease and stroke: a meta-analysis. JAMA 2002; 288:2015-22.

3. Hujar BS, Kopyta I, Skrzpek M. Is the $1298 \mathrm{~A}>\mathrm{C}$ polymorphism in the MTHFR gene a risk factor for arterial ischaemic stroke in children? The results of meta-analysis. Clin Exp Med 2018;18:337-45.

4. Mallick AA, Ganesan V, Kirkham FJ, Fallon P, Hedderly T, McShane $T$, et al. Childhood arterial ischaemic stroke incidence, presenting features, and risk factors: a prospective population-based study. Lancet Neurol 2014;13(1):35-43.

5. Lo WD, Kumar R. Arterial ischemic stroke in children and young adults. Continuum (Minneap Minn) 2017;23:158-80. 
B. N. Karacabey ve ark., MTHFR A1298C Homozigot Gen Polimorfizmi Olan Süt Çocuğunda Akut İskemik İnme: Olgu Sunumu

6. Felling RJ, Sun LR, Maxwell EC, Goldenberg N, Bernard T. Pediatric arterial ischemic stroke: epidemiology, risk factors, and management. Blood Cells Mol Dis 2017;67:23-33.

7. Strater R, Kurnik K, Heller C, Schobess R, Luigs P, Nowak-Gottl $U$. Aspirin versus low-dose low- molecular-weight heparin: antithrombotic therapy in pediatric ischemic stroke patients: a prospective follow-up study. Stroke 2001;32(11):2554-8.
8. Clarke R, Armitage J. Vitamin supplements and cardiovascular risk: review of the randomized trials of homocysteine-lowering vitamin supplements. Semin Thromb Hemost 2000;26:341-8.

9. Simonetti BG, Cavelti A, Arnold M, Bigi S, Regényi M, Mattle HP, et al. Long-term outcome after arterial ischemic stroke in children and young adults. Neurol 2015;84(19):1941-7. 